\title{
PENGARUH PARADIGMA LINGKUNGAN DAN PERSONAL VALUE TERHADAP CARBON FOOTPRINT MAHASISWA
}

\author{
Ali Sibro Malisi ${ }^{1 *}$, Nadiroh

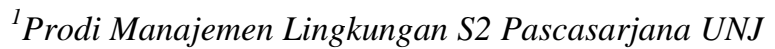

Email: ali.sibro.m@gmail.com

\begin{abstract}
The objective of the research was aimed to finding the influence of environmental paradigm and personal value on environmental issues. Here, the effect of environmental paradigm and personal value on environmental using Carbon Footprint Analysis were evaluated on students at Universitas Negeri Jakarta. This research uses quantitative expost facto method with sample of 194 students. The results showed that there is influence of environmental paradigm and personal value to total carbon footprint of student. It is known that the student's carbon footprint which has DSP paradigm is bigger than the student with NEP paradigm. This also applies to personal values, it is known that students who have egoistic personal values have a greater carbon footprint than those with personal value altruistic and biospheric. Based on the results of this study, it can be concluded carbon footprint is affected by environmental paradigm and personal value.
\end{abstract}

Keywords: carbon footprint, environmental paradigm, personal value, sustainability 


\section{PENDAHULUAN}

Perubahan iklim dan pengurangan emisi GRK adalah agenda utama kebijaksanaan lingkungan masyarakat dunia untuk saat ini. Berdasarkan prinsip manajemen karbon yang dibuat oleh Enviromental Protection Agency (EPA), hal pertama yang harus dilakukan apabila suatu organisasi ingin melakukan manajemen karbon organisasinya adalah dengan mengetahui jumlah gas rumah kaca yang dihasilkan oleh organisasinya.Oleh karena itu, untuk mendukung rencana aksi mitigasi ini diperlukan data-data yang terkait dengan jumlah gas rumah kaca yang dihasilkan dari konsumsi energi dan kegiatan lain yang merupakan sumber emisi karbon.

Satu indikator dalam perhitungan karbon adalah carbon footprint. Metode ini digunakan untuk menghitung semua emisi langsung dan tidak langsung gas rumah kaca secara spesifik dari ruang lingkup satu (emisi dari proses langsung pembakaran bahan bakar fosil), ruang lingkup dua (emisi tidak langsung dari pembelian listrik) dan ruang lingkup tiga (emisi tidak langsung yang disebabkan dari pembelian barang dan jasa)

Dalam kaitannya dengan pembangunan berkelanjutan (Sustainable
Development), analisis Carbon Footprint saat ini telah banyak digunakan sebagai indikator keberlanjutan suatu lingkungan. Carbon Footprint dapat digunakan untuk mengukur besaran dampak yang dihasilkan dari aktivitas manusia dalam mengkonsumsi sumber daya alam yang tersedia sehingga dapat dijadikan alat untuk perencanaan menuju pemanfaatan sumber daya alam secara berkelanjutan.

Penelitian yang fokus untuk mengukur Carbon Footprint pada lingkungan institusi pendidikan telah cukup banyak dilakukan. Sebagian besar penelitian tersebut merupakan penelitian deskriptif yang mengungkap Carbon Footprint dari dua sisi, yaitu: kelompok manusia dan keseluruhan institusi.

Sprangers (2011) mengukur Carbon Footprint seluruh komponen di Erasmus University Rotterdam, meliputi aset milik kampus, energi listrik dan transportasi yang digunakan serta aktivitas mahasiswa dan karyawan. Hasil penelitian tersebut menunjukkan emisi $\mathrm{CO}_{2}$ total EUR adalah 12,6 juta $\mathrm{kg} \mathrm{CO}_{2}$ pada tahun 2010. Transportasi menjadi penyumbang terbesar, dengan rincian emisi transportasi mahasiswa sebesar $61,6 \%$, dan karyawan 13,2\%. Selain 
itu sumber emisi lainnya adalah pembelian panas $(12,6 \%)$, pembelian tenaga listrik $(7,3 \%)$ dan perjalanan karyawan $(2,7 \%)$.

Larsen et al. (2013) menerapkan model Environmentally Extended Input Output (EEIO) untuk menghitung Carbon Footprint dari Universitas Norwegia Teknologi dan Sains (NTNU). Hasil penelitian menunjukkan bahwa Carbon Footprint dari NTNU sangat signifikan dengan kontribusi rata-rata 4,6 ton per mahasiswa. Secara khusus, pembelian peralatan dalam jumlah besar dan bahan habis pakai untuk digunakan dalam laboratorium menjadi penyumbang Carbon Footprint terbesar. Jika dihitung berdasarkan fakultas diperoleh hasil bahwa mahasiswa fakultas ilmu sosial dan humaniora memiliki Carbon Footprint lebih rendah dibandingkan mahasiswa fakultas sains, teknik dan kedokteran.

Keterkaitan antara paradigma lingkungan dan personal value dengan permasalahan lingkungan masih belum dipelajari secara mendalam. Selain itu, sedikitnya penelitian yang telah terpublikasi umumnya hanya mengkaji kaitan antara personal value dengan sikap dan pengetahuan terhadap lingkungan, terutama pada kasus perubahan iklim.
Paradigma lingkungan adalah kecenderungan seseorang yang diwujudkan dalam bentuk keyakinan dan praktek standar tentang lingkungan yang dikonstruksikan atau dikerangkakan dalam pikiran manusia, kemudian dijadikan pedoman mendasar manusia ketika berinteraksi dengan lingkungannya dan tindakan manusia dalam mengelola lingkungan. Personal value adalah nilai adalah suatu keyakinan mengenai cara bertingkah laku dan tujuan akhir yang diinginkan individu, dan digunakan sebagai prinsip atau standar dalam hidupnya.

Stern dan Dietz (1994) dalam Rauwald dan Moore (2002) menyatakan bahwa sikap seseorang terhadap lingkungan dipengaruhi oleh kelompok nilai. Selain itu, Cotgrove (1982) dalam Stern et al. (1999) menyatakan bahwa nilai personal merupakan faktor paling penting untuk membedakan individu yang memperhatikan kelestarian lingkungan (environmetalist) dan yang tidak memperhatikan kelestarian lingkungan (non environmetailist).

Schultz (2001) menguji hubungan antara nilai egoistic, altruistic, dan biospheric dan perhatian terhadap lingkungan. Sampel dalam penelitian ini adalah 1.010 mahasiswa S1 Psikologi di beberapa universits Amerika 
Serikat. Dalam penelitian ini, partisipan diminta untuk menilai 12 item tentang alasan responden memberi perhatian terhadap lingkungan. Partisipan dalam penelitian ini adalah mahasiswa ilmu sosial di 10 negara Amerika Latin. Penelitian ini menggunakan instrumen skala NEP (Dunlap et al. 1992, Dunlap, et al. 2001), skala ecosentrism dan antropocentrism (Thompson dan Barton's, 1994), nilai Schwartz (1992, 1994), 12 item tentang alasan responden memberi perhatian terhadap lingkungan. Hasilnya, bahwa ketiga nilai tersebut (egoistic, altruistic, dan biospheric) sesuai untuk menguji hubungan antara nilai tersebut dengan perhatian terhadap lingkungan. Dengan menggunakan skala nilai Schwartz (1992, 1994), Schultz menemukan bahwa egoistic concern berhubungan positif dengan selfenhancement dan berhubungan negatif dengan dan biospheric transcedence. Sebaliknya, biospheric concern (perhatian terhadap biosphere) berhubungan negatif dengan self-enhancement dan berhubungan posistif dengan biospheric transcedence.

Berdasarkan beberapa penelitian mengenai carbon footprint di atas, baru sebatas menghitung total carbon footprint yang dihasilkan kampus, belum menyelidiki lebih jauh mengenai faktor apa saja yang mempengaruhi total carbon footprint sehingga dapat dilakukan upaya mitigasi untuk pengurangan carbon footprint secara berkelanjutan.

Selanjutnya dalam penelitian ini akan dikaitkan antara carbon footprint dengan paradigma dan personal value. Sebagaimana penelitian yang telah dilakukan oleh Schultz dan Stern yang mengaitkan antara value dengan sikap terhadap lingkungan. Maka kali ini sikap terhadap lingkungan diukur dengan analisis carbon footprint.

\section{METODOLOGI}

Tujuan penelitian ini adalah mengetahui perbedaan komponen Carbon Footprint mahasiswa di Universitas Negeri Jakarta berdasarkan paradigma lingkungan dan personal value. Untuk memperoleh nilai Carbon Footprint tiap mahasiswa, metode ex-post facto digunakan untuk merekam konsumsi dari 194 mahasiswa melalui kuisioner. Validasi kuisioner dalam penelitian ini menggunakan validasi ahli. Teknik pengambilan data menggunakan tiga instrumen variabel yang akan dikaji, yaitu Carbon Footprint (Y), Paradigma Lingkungan (A) dan Personal value (B). Setiap instrumen penelitian berpedoman 
pada konsepsional yang meliputi definisi konseptual, definisi operasional, kisi-kisi instrumen penelitian, validitas instrumen dengan teknik korelasi Pearson Product Moment dan perhitungan reliabilitas dengan rumus korelasi Alpha Cronbach. Teknik analisis data meliputi: (1) statistik diskriptif berupa skor rata-rata, median, modus, simpangan baku, dan distribusi frekuensi kumulatif. (2). Uji hipotesis dengan menggunakan ANAVA dua arah.

\section{HASIL DAN PEMBAHASAN}

Penelitian ini melibatkan tiga variabel, yaitu Carbon Footprint sebagai variabel terikat (Y), Paradigma Lingkungan (A) dan Personal Value (B) sebagai variabel bebas. Adapun secara rinci pembahasan hasil analisis dan pengujian hipotesis penelitian diuraikan sebagai berikut:

\section{Pengaruh paradigma lingkungan terhadap carbon footprint mahasiswa}

Tabel 1. Hasil Uji ANOVA variabel A dan B

Pengujian hipotesis pertama dengan menggunakan uji anova dua arah adalah untuk menguji pengaruh main effect yakni pengaruh paradigma lingkungan (A) $\operatorname{DSP}\left(\mathrm{A}_{1}\right)$ dan $\mathrm{NEP}\left(\mathrm{A}_{2}\right)$ total carbon footprint mahasiswa (Y).
Uji hipotesis pertama dimaksudkan untuk menguji apakah benar adanya bahwa, "total carbon footprint kelompok paradigma paradigma dominan sosial/DSP $\left(\mathrm{A}_{1}\right)$ berbeda dengan paradigma lingkungan baru/NEP $\left(\mathrm{A}_{2}\right)$ ". Kriteria uji yang digunakan adalah tolak Ho jika nilai $\mathrm{F}$ hitung lebih besar daripada $\mathrm{F}$ tabel pada alfa $=0,05$.

Berdasarkan Tabel 1 di atas, diketahui bahwa pada kelompok paradigma lingkungan menunjukkan angka $\mathrm{F}$ hitung sebesar 22,64. Oleh karena angka F hitung lebih besar dari F tabel $(22,64>3,09)$, maka dapat diinterpretasikan jika "terdapat perbedaan total carbon footprint mahasiswa yang memiliki paradigma dominan sosial/DSP $\left(\mathrm{A}_{1}\right)$ dengan yang memiliki paradigma lingkungan baru/NEP $\left(\mathrm{A}_{2}\right)$ "”

Selanjutnya berdasarkan perhitungan total carbon footprint diperoleh hasi sebagai berikut:

\begin{tabular}{|c|c|c|c|c|c|}
\hline Source & df & $\begin{array}{c}\text { Mean } \\
\text { Square }\end{array}$ & Fhitung & $\begin{array}{c}\text { Ftabel } \\
(0.05)\end{array}$ & Sig. \\
\hline $\begin{array}{c}\text { Paradigma } \\
\text { Lingkungan (A) }\end{array}$ & 1 & $\begin{array}{c}3,833 \mathrm{E}+0 \\
7\end{array}$ & 22,640 & 3.09 &, 000 \\
\hline $\begin{array}{c}\text { Personal Value } \\
(\mathrm{B})\end{array}$ & 2 & $\begin{array}{c}1,754 \mathrm{E}+0 \\
7\end{array}$ & 10,359 & 3.09 &, 000 \\
\hline $\begin{array}{c}\text { Interaksi A * B } \\
\text { Total }\end{array}$ & 2 & $\begin{array}{c}1,610 \mathrm{E}+0 \\
7\end{array}$ & 9,510 & 3.09 &, 000 \\
\hline
\end{tabular}




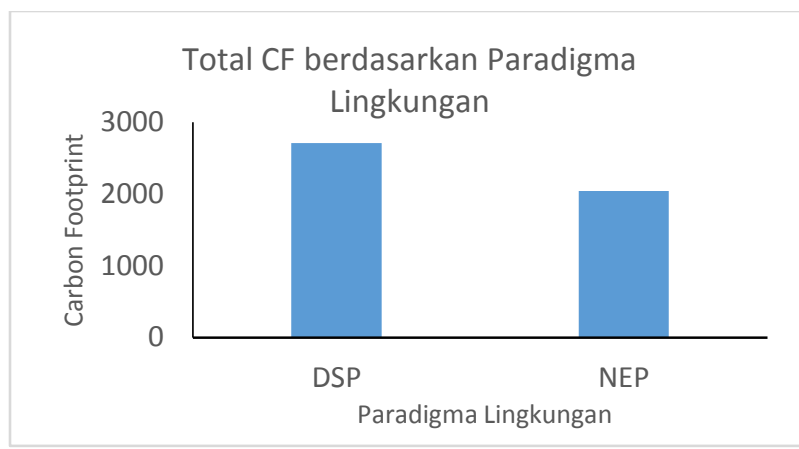

Gambar 1.

Grafik perbandingan CF berdasarkan paradigma lingkungan

Berdasarkan gambar 1 di atas carbon footprint diperoleh hasil bahwa carbon footprint yang dihasilkan mahasiswa yang memiliki paradigma DSP lebih besar dibandingkan dengan carbon footprint yang dihasilkan mahasiswa berparadigma NEP. Hal ini sesuai dengan teori mengenai paradigma lingkungan baru (NEP) yang merupakan sebuah pandangan baru bagaimana manusia bersikap terhadap lingkungan, dalam pemenuhan kebutuhannya manusia harus memperhatikan keber-langsungan lingkungan hidup.

\section{Pengaruh personal values terhadap carbon footprint mahasiswa}

Pengujian hipotesis kedua adalah untuk menguji pengaruh personal value egoistic $\left(\mathrm{B}_{1}\right)$, altruistic $\left(\mathrm{B}_{2}\right)$ dan biospheric $\left(\mathrm{B}_{2}\right)$ terhadap total carbon footprint (Y).
Uji hipotesis kedua dimaksudkan untuk menguji apakah benar adanya bahwa, "total carbon footprint kelompok personal value egoistic $\left(\mathrm{B}_{1}\right)$ berbeda dengan personal value altruistic $\left(\mathrm{B}_{2}\right)$ dan personal value biospheric $\left(\mathrm{B}_{3}\right)$ ". Kriteria uji yang digunakan adalah tolak Ho jika nilai $\mathrm{F}$ hitung lebih besar daripada $F$ tabel pada alfa $=0,05$.

Berdasarkan Tabel 1 di atas, diketahui bahwa pada kelompok paradigma lingkungan menunjukkan angka $\mathrm{F}$ hitung sebesar 10,59. Oleh karena angka F hitung lebih besar dari F tabel $(10,59>3,09)$, maka dapat diinterpretasikan jika "terdapat perbedaan total carbon footprint mahasiswa yang memiliki personal value egoistic $\left(\mathrm{B}_{1}\right)$ berbeda dengan personal value altruistic $\left(\mathrm{B}_{2}\right)$ dan personal value biospheric $\left(\mathrm{B}_{3}\right)$ ".

Untuk mengetahui lebih jelas perbedaan carbon footprint berdasarkan personal value dengan menghitung total carbon footprint antara value egositic, altruistic, dan biospheric yang dihasilkan dalam gambar 2 berikut: 


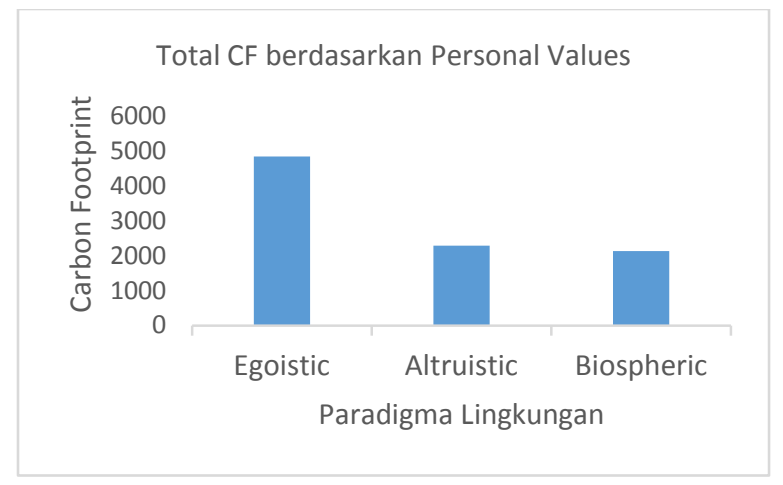

Gambar 2. Grafik perbandingan CF berdasarkan personal value

Berdasarkan grafik terlihat adanya perbedaan yang cukup signifikan total carbon footprint antara value egoistic dengan altruistic maupun biospheric. Namun jika dibandingkan total carbon footprint antara value altruistic dengan biospheric tidak terdapat perbedaan yang signifikan. Total carbon footprint value altruistic sedikit lebih besar dibandingkan biospheric. Hal sesuai dengan yang dinyatakan oleh Schultz (2001) dengan menggunakan skala nilai Schwartz (1992, 1994), bahwa egoistic concern berhubungan positif dengan self-enhancement dan berhubungan negatif dengan biospheric transcedence. Sebaliknya, biospheric concern (perhatian terhadap biosphere) berhubungan negatif dengan selfenhancement dan berhubungan posistif dengan biospheric transcedence.

\section{Interaksi antara paradigma} lingkungan dan personal value dalam mempengaruhi carbon footprint

Uji hipotesis ketiga dimaksudkan untuk menguji apakah benar adanya bahwa, "terdapat pengaruh interaksi antara paradigma lingkungan (A) dan personal value (B) terhadap total carbon footprint mahasiswa (Y)”.

Berdasarkan hasil uji pada Tabel 1, diketahui bahwa nilai F hitung (9.510) lebih besar daripada F tabel (3.09), yang berarti tolak H0. Hasil uji ini memberikan bukti secara empirik bahwa, "terdapat interaksi antara paradigma lingkungan dengan personal value dalam mempengaruhi total carbon footprint mahasiswa".

\section{KESIMPULAN}

Berdasarkan penelitian ini, kesimpulan yang didapat adalah adanya pengaruh personal value, dalam hal ini adalah egoistic, altruistic dan biospheric terhadap total carbon footprint mahasiswa. Secara rinci pengaruh yang diberikan adalah value egoistic memberikan kontribusi carbon footprint lebih besar daripada value altruistic dan biospheric. Serta value biospheric memiliki kontribusi carbon footprint paling kecil dibandingkan egoistic 
dan altruistic. Selain itu, paradigma lingkungan juga memberikan pengaruh yang signifikan dalam memberikan kontribusi terhadap carbon footprint. Diketahui bahwa pada mahasiswa yang memiliki paradigma NEP menghasilkan carbon footprint lebih kecil dibandingkan mahasiswa yang memiliki paradigma DSP.

\section{DAFTAR PUSTAKA}

Bartlett II, James E., Joe W Kotrlik Joe W Kotrlik, and Chadwick C Higgins Chadwick C Higgins. "Organizational Research: Determining Appropriate Sample Size in Survey Research Appropriate Sample Size in Survey Research." Information technology, learning, and performance journal 19, no. 1 (2001): 43

B.,Robert, Bechtel, and Arza Churchman. Handbook of Environmental Psychology. New York: John Wiley \& Sons, Inc., 2003.

Chiras, Daniel D. Environmental Science: Creating Sustainable Future. USA: John \& Bartleet Publisher, Inc., 2001

Cohen, Steven. Understanding Environmental Policy. New York: Columbia University PresS, 2006.

Dunlap, Riley E. “The New Environmental Paradigm Scale: From Marginality to Worldwide Use." Journal of

Environmental Education 40. 2008.

Federation, Australian Nursing. "Submission to Consultation by the Department of Education, Employment and Workplace Relations on the Discussion Papers: An Indicator Framework for Higher Education Performance Funding; and Measuring the Socio-Economic Status of Higher Education Students." Canberra: Australian Nursing Federation. 2010.

Fransson, N., \& Garling, T. Environmental concern: Conceptual definitions, measurement methods, and research finding. Journal of Environmental Psychology, 19, 1999.

Groot, Judith \& Steg, Linda. "Value Orientations to Explain Beliefs Related to Environmental Significant Behavior" Environment and Behavior Vol 40 Number 3. 2008.

Patel, Rituma. Environmental Beliefs, Value and Worldviews: Etiology. USA: Proquest LLC, 2008.

Preacher, Kristopher J, Derek D Rucker, Robert C MacCallum, and W Alan Nicewander. "Use of the Extreme Groups Approach: A Critical Reexamination and New Recommendations." Psychological methods 10, no. 2.2005 .

Redclift, Michael R., and Graham Woodgate. Handbook of Environmental Sociology Edward Elgar Publishing, Inc. USA: Edward Elgar Publishing, Inc., 2010.

Schultz, P. W. and L. Zelezny. "Values as Predictors of Environmental Attitudes: Evidence for Consistency across 14 Countries", Journal of Environmental Psychology. 1999. 
Schultz, P. W. The structure of environmental concern for self, other people and the biosphere. Journal of Environmental Psychology, 21. 2001.

Schultz, Wolfram. "Measuring the SocioEconomic Background of Students and Its Effect on Achievement on PISA 2000 and PISA 2003." Online Submission. 2005.

Schwartz, S. H. Are There Universal Aspects in the Structure and Contentsof Human Values? Journal of Social Issues, 50. 1994.

Selle, Per, Oystein Bortne, and Kristin Stormsnes. Unique Environmentalism a Comparative Perspective: Anthropocentrism vs Ecocentrism NEP. googlebooks, 2006

Spranger, Stefan. Calculating the carbon footprint of universities- a case study of Erasmus University Rotterdam. 2011

Stern, Paul C, et.al. "A Value-Belief-Norm Theory of Support for Social Movements : The Case of Environmentalism" Human Ecology Review, vol 6, No 2. 1999.

Suhedi F.Emisi CO2 dari Konsumsi Energi Domestik. (Jakarta : Pusat Litbang Permukiman Departemen Pekerjaan Umum. 2005.

The Berkshire Encyclopedia Of Sustainability: Measurements, Indicators, And Research Methods For Sustainability. Berkshire Publishing Group, 2012. www.berkshirepublishing.com.

Wackernagel, Mathis, and William E Rees. Our Ecological Footprint: Reducing
Human Impact on the Earth. Gabriola Island, Canada: New Society Publ., 1996.

Walser, M.L. Carbon footprint. Articles of Encilopedia of Earth. 2010.

Wiedmann, T. dan Minx, J. A Definition of 'Carbon Footprint'. In: C. C. Pertsova, Ecological Economics Research Trends: Chapter 1. Nova Science Publishers, Hauppauge NY. 2008 